\title{
Overweight in urban, low-income, African American and Hispanic children attending Los Angeles elementary schools: research stimulating action
}

\author{
Wendelin M Slusser*, William G Cumberland, Ben L Browdy, Donna M Winham and \\ Charlotte G Neumann \\ UCLA School of Public Health, Box 951772, Los Angeles, CA 90095-1772, USA
}

Submitted 13 November 2003: Accepted 8 September 2004

\begin{abstract}
Objective: This study was undertaken to establish the prevalence and severity of nutritional problems among low-income children of elementary school age in the Los Angeles Unified School District (LAUSD) in order to collect baseline data to inform policy-makers.

Design and methods: A cross-sectional survey of children in 14 elementary schools was conducted from January to June, 1998. Nine hundred and nineteen children were measured and interviewed. The planning, design and data analysis were carried out in collaboration with key LAUSD policy-makers.

Results: More than 35\% of the sample was classified as being at risk for overweight or overweight according to body mass index.

Conclusion: There is a high prevalence of children who are at risk for overweight or who are overweight in Los Angeles. This finding has triggered the development of multiple school-based intervention programmes.
\end{abstract}

Overweight among children carries heavy individual and public health consequences and is on the rise in the United States $^{1-4}$. In less than 30 years, the rates of overweight among children and adolescents have more than doubled $^{5}$. In the 1999-2000 National Health and Nutrition Examination Survey (NHANES III), 15.5\% of adolescents aged $12-19$ years, and $15.3 \%$ of children aged $6-11$ years, were overweight compared with $10.5 \%$ and $11.3 \%$ respectively in 1988-1994 (NHANES III) ${ }^{5}$. Reports from the Centers for Disease Control and Prevention (CDC) indicate that overweight is occurring in children as early as pre-school age ${ }^{6,7}$, with NHANES III (1999-2000) reporting that $10.4 \%$ of children aged $2-5$ years are overweight ${ }^{5}$.

Overweight children not only suffer from negative psychosocial interactions and repercussions from their peers, sleep apnoea and orthopaedic complications, but older overweight children and adolescents are now also presenting with type II diabetes mellitus and hypertension, diseases normally seen in the obese adult and/or the elderly ${ }^{8,9}$. The overweight child is also at much higher risk for becoming an overweight adult ${ }^{3,4}$ : approximately 30\% of overweight children become overweight adults ${ }^{10}$. The persistence of overweight into adulthood results in more extreme overweight as an adult, with higher morbidity and mortality than experienced in adults whose overweight began in adulthood ${ }^{9-11}$. Therefore programmes to promote healthy lifestyles need to start early in life, to prevent overweight in childhood and subsequently adulthood.

In 1998, we undertook a cross-sectional study to establish the prevalence, distribution and severity of nutritional problems and their main determinants among a sample of children, from low-income families, attending elementary schools in the Los Angeles Unified School District (LAUSD). This information was collected to help policy-makers identify nutritional problems among children in LAUSD and in turn translate these findings into ways to help improve the nutritional status of children attending elementary schools. This aim of translational research has been described by the National Institutes of Health as a means to apply scientific research to public health issues to "translate science into action',12

No previous comprehensive study had ever been carried out regarding the food situation and nutritional status of multi-grade children of elementary school age in the LAUSD, the second largest school district in the USA. The present paper reports only the anthropometric findings and the subsequent action stimulated by this study.

\section{Design and methods}

During all of the planning phases of this study, LAUSD policy-makers were kept informed and involved in the study design. 


\section{Sample}

A cross-sectional study of schoolchildren in 14 elementary schools in LAUSD was conducted during January 1998 to June 1998. Schools were selected by a stratified, singlestage, cluster sampling procedure from geographic areas chosen to target children of Hispanic, African American, Asian American and Caucasian origin with low socioeconomic status.

The LAUSD covers 704 square miles within Los Angeles County. It is the second largest school district in the USA with a total of 730000 students in grades $\mathrm{K}-12$. The district is separated into 11 local districts. Because the LAUSD is so large geographically, the sampling frame included only schools in LAUSD that were located in the central region of the district defined by census tracts of Los Angeles County. Only elementary schools (5-11year-olds) that had more than $65 \%$ of their students eligible for the federal government subsidised free or reduced school lunch programme were included in the study in order to sample children mostly living in lowincome households. Only 19 of the 244 elementary schools in the central region of LAUSD did not meet these qualifications.

Since over $70 \%$ of the student population in the LAUSD is Hispanic, the remaining 225 schools were stratified by racial and ethnic composition to capture other racial and ethnic groups in addition to Hispanic children. Schools were stratified by race/ethnicity into the following groups: predominantly (80-100\%) Hispanic, majority (50-79\%) Hispanic, predominantly (80-100\%) African American, majority (50-79\%) African American, predominantly white $(>40 \%)$ and/or Asian (>40\%), or mixed (no predominant racial group). Within each stratum, the schools were chosen randomly to approximate the actual proportions of each ethnic group in the school district in the final sample as follows: 6/122 from the predominantly Hispanic group, 3/67 from the majority Hispanic group, 2/12 from the predominantly African American group, 1/11 from the majority African American group, 1/6 from the predominantly white and/or Asian group, and 1/7 from the mixed group.

A total of 14 schools were, therefore, chosen to be part of the study. Principals from eight of the original 14 schools chosen declined to participate for the following reasons: three lacked space for the study, one participated in too many studies, one did not like the study, two gave no reason and one was substituting for the principal who was on family leave. When a principal declined, another school was chosen randomly from the same racial/ethnic group. The demographic data were provided by the Information Technology Division of the Information Center Branch of LAUSD. No special education or gifted classes were included in the study. The target number of children was 20-30 per class, with one to two classrooms included in the study at each grade level, depending on class size. Participation by the children was strictly voluntary and ranged from 25 to $100 \%$ of students in each classroom approached. If there was a low response rate in one classroom another classroom at the same grade level was added to participate in the study. Investigation of parental reasons for not participating in the study was not feasible because of logistical reasons. The children who participated at each of the schools represented the racial and ethnic make-up of the general population of the school. Since this study was strictly voluntary, we had no control over how many of the children participated in each of the classrooms. This could have created a selection bias where the parents and/or children who were more motivated or concerned about nutritional issues participated in the study.

\section{Anthropometric measurements}

Body measurements to assess nutritional status included weight, height and triceps skinfold thickness (TSF). Weight was measured on a Seco beam balance to the nearest $100 \mathrm{~g}$ with shoes and heavy outer garments removed. Height was measured to the nearest $0.1 \mathrm{~cm}$ using a stadiometer height board; shoes were removed and hair flattened maximally. TSF was measured to the nearest $0.5 \mathrm{~mm}$ using Lange skinfold callipers, with three measurements taken and then averaged. Methods are described fully elsewhere ${ }^{13,14}$. Body mass index (BMI) was obtained by dividing weight in kilograms by the square of height in metres. Ages were calculated from the birth dates of the children and the date on which measurements were made.

Two research assistants, who were trained by a physician and a nutritionist, experienced in anthropometry, obtained all of the measurements in the study. The survey team comprised a multicultural and multiracial group of women and men. Periodic standardisation tests and retraining sessions were held. For quality control purposes, measurements were repeated by one or two supervisors on the same day as the original measurement on a $5 \%$ sub-sample, to determine percentage agreement with the 'expert'. Ninety-four per cent of height measurements were within $1 \mathrm{~cm}$ and $96 \%$ of weight measurements were within $0.5 \mathrm{~kg}$. Eighty-six per cent of the TSF measurements were within $3 \mathrm{~mm}$. The TSF measurements were difficult to obtain on the very overweight children and this may account for the lower percentage agreement.

Prior approval to conduct this study was given by the Committee on Research Studies of the LAUSD Program Evaluation and Assessment Branch, the school principals, and the UCLA Human Subjects Protection Committee. Informed written consent was obtained from parents or guardians, and the children signed assent forms after they were given a verbal explanation of the study. All consent forms and letters were written in fifth-grade English and translated into Spanish, Mandarin, Vietnamese and Korean, then translated back into English. 
Criteria and definitions for underweight, risk for overweight and overweight

Risk for being overweight was defined as having weightfor-age (WA) in the range $110-119 \%$ of the median, or BMI in 85th-94th percentile, or TSF in 85th-94th percentile. Overweight was defined as WA $\geq 120 \%$ of the median, or BMI $\geq 95$ th percentile, or TSF $\geq 95$ th percentile ${ }^{15-20}$. Underweight was defined as WA $<80 \%$ of the median. Because the degree of overweight increases the long-term health risks among children, we teased out two categories within the definition of overweight for weight-for-age: overweight (WA $\geq 120-159 \%$ of the median) and 'super' overweight (WA $\geq 160 \%$ of the median).

\section{Data analyses}

Data input and analysis were conducted using the EPI INFO anthropometric program version $6.02^{15}$. Growth reference data from the National Center for Health Statistics (NCHS)/CDC were used to determine percentage of the median for $\mathrm{WA}^{18}$. Percentiles for TSF were based on reference data from NHANES I and $\mathrm{II}^{17,18}$. CDC/NCHS percentile reference values for BMI were used ${ }^{19}$.

The prevalences of at risk for overweight and overweight are unadjusted for the cluster design and the oversampling for African American children.

\section{Results}

Data are reported for nine hundred and nineteen children in grades 2 to 5 (aged 7-11 years) in 14 elementary schools (grades kindergarten to 5th grade, 5-11-yearolds) in LAUSD. Schools ranged in size from 336 to 1461 students, with an average of 830 students in each school. The sample contained a slightly higher proportion of females (56.4\%) than males (43.6\%). Hispanic children made up over half of the sample $(56.8 \%)$, followed by African Americans comprising nearly a quarter (23.7\%) and Asians nearly a tenth of the sample (8.7\%). The racial and ethnic mix of the children participating in the study reflected the overall student body of the 14 schools: 10\% Asian, 23\% African American and 61\% Hispanic. Caucasians, South Pacific Islanders and other racial and ethnic groups comprised a small percentage of the remainder of the sample (total 10.2\%). The sample had approximately equal numbers of children from each grade level $25.8 \%$ in 2nd grade, $7-8$-year-olds; $24.6 \%$ in 3rd grade, $8-9$-yearolds; $23.4 \%$ in 4 th grade, $9-10$-year-olds; and $25.3 \%$ in 5 th grade, 10-11-year-olds).

\section{Anthropometric findings}

\section{Weight-for-age}

Some $12.2 \%$ of children were at risk for overweight (WA $110-119 \%$ of the median) and $28.6 \%$ were overweight (WA $\geq 120-159 \%$ of the median). The prevalence of 'super' overweight or obese (WA $\geq 160 \%$ of the median) was $11.7 \%$. Therefore, a total of $40.3 \%$ of the children in our sample were overweight. A total of $52.5 \%$ of the children were at risk for overweight or overweight.

Slightly more males (42.6\%) than females (38.8\%) were overweight, especially in the heavier group (WA $\geq 160 \%$ of the median) (Fig. 1). The racial/ethnic groups with the highest percentage of obesity were the African Americans (46.5\%) and Hispanics (41.2\%) (Fig. 2). Other racial and ethnic groups were not included in the analysis due to the small sample size. The percentages of overweight children were similar across grades (2-5, ages $7-11$ years) (see Fig. 3).

Only $4 \%$ of the sample was underweight (WA $<80 \%$ of the median). Among Asian American children, 14\% were underweight.

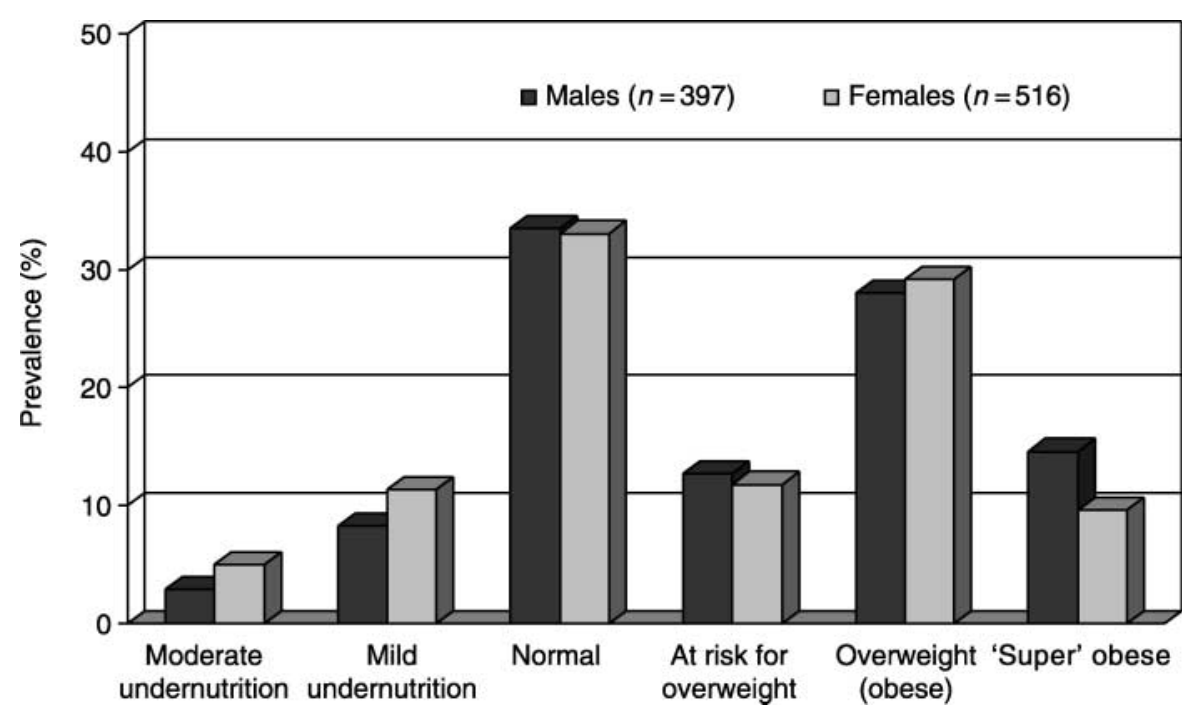

Fig. 1 Weight-for-age by sex (based on $\%$ of the median using growth reference data from the National Center for Health Statistics/Centers for Disease Control and Prevention ${ }^{18}$ ) 


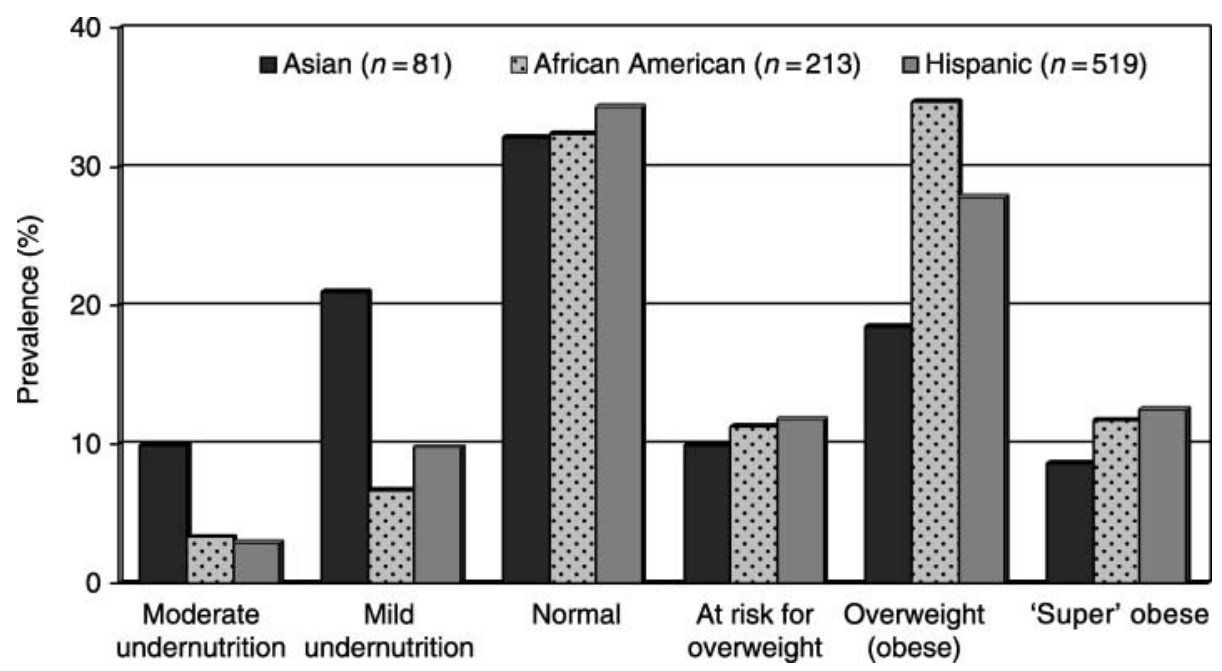

Fig. 2 Weight-for-age by race/ethnicity (based on \% of the median using growth reference data from the National Center for Health Statistics/Centers for Disease Control and Prevention ${ }^{18}$ )

\section{Body mass index}

Using the newly recommended CDC/NCHS cut-offs for $\mathrm{BMI}^{19}, 37.6 \%$ of all grades and sexes combined were at risk for overweight or overweight (BMI $>85$ th percentile). More males (42.5\%) than females (33.8\%) were at risk for overweight or overweight. Hispanics had the highest prevalence of being at risk for overweight or overweight (42.5\%), followed by African Americans (34.3\%) and Asian Americans (21.8\%). By age and grade, $37 \%$ of children at age $7-8$ years (grade 2 ) were already at risk for overweight or overweight, with increases to $42.6 \%$ by ages 10 and 11 years (grade 5) (Table 1).

\section{Triceps skinfold}

TSF is a direct anthropometric measure of body fat as most of the fat in children is subcutaneous ${ }^{21}$. When using TSF $\geq 95$ th percentile value as a criterion for obesity based on NHANES $\mathrm{II}^{18}, 59 \%$ of the sample was considered to be overweight. This measure gives a higher estimate of overweight than WA or BMI. This higher estimate may have been due to the technical difficulty in obtaining accurate TSF measurements in severely overweight children $^{21}$.

\section{Discussion}

This is the first study systematically to document the high prevalence of children who are at risk for overweight or overweight in predominantly poor minorities in Los Angeles elementary schools. These rates are considerably higher than those found in US national surveys ${ }^{1,3,5}$. Of significance is that there is a high prevalence of overweight among 7-8-year-old children (grade 2) in the study. There is a higher prevalence of at risk for overweight and overweight among boys than among girls in this study. NHANES III also reported a difference

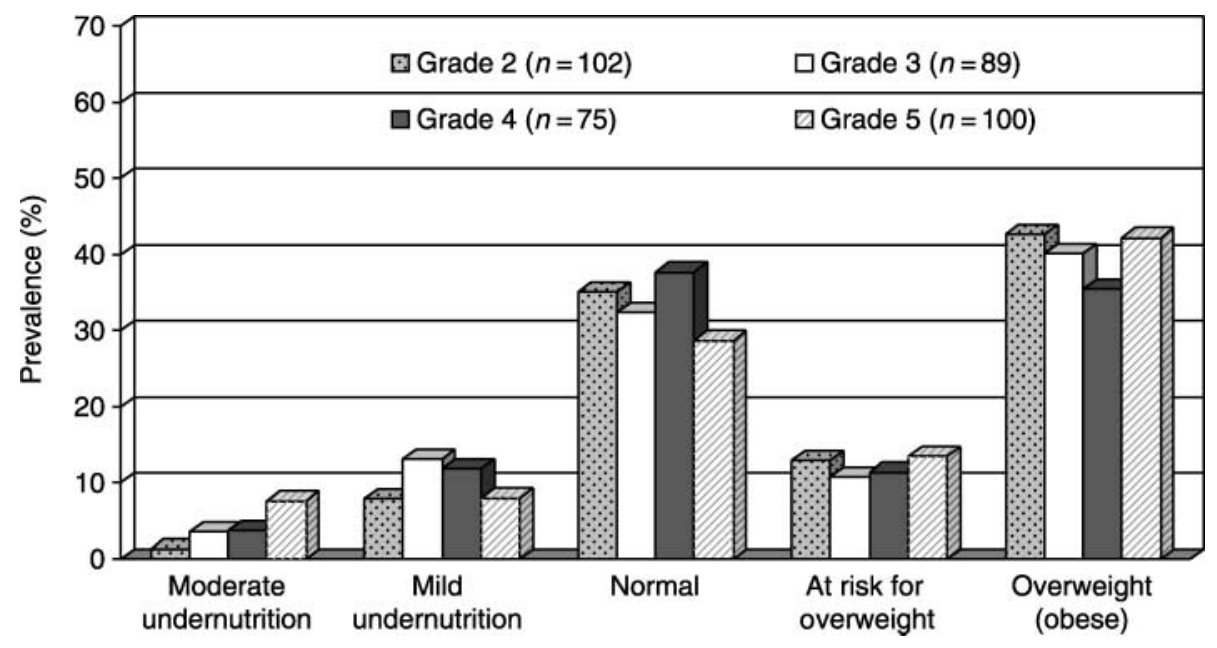

Fig. 3 Weight-for-age by grade (based on \% of the median using growth reference data from the National Center for Health Statistics/Centers for Disease Control and Prevention ${ }^{18}$ ) 
Table 1 Prevalence of overweight by body mass index (BMl; based on percentile reference values from the Centers for Disease Control and Prevention/National Center for Health Statistics $\left.{ }^{19}\right)(n=919)$

\begin{tabular}{lccc}
\hline & \multicolumn{3}{c}{ Prevalence (\%) } \\
\cline { 2 - 4 } Group & $\begin{array}{c}\text { At risk for overweight } \\
\text { (BMI in 85th-94th percentile) }\end{array}$ & $\begin{array}{c}\text { Overweight } \\
\text { (BMI } \geq 95 \text { th percentile) }\end{array}$ & $\begin{array}{c}\text { Total at risk } \\
\text { or overweight }\end{array}$ \\
\hline Sex & & & \\
$\quad$ Male & 13.1 & 29.4 & 42.5 \\
Female & 13.8 & 20.0 & 33.8 \\
$\quad$ Total & 13.5 & 24.1 & 37.6 \\
Race/ethnicity & 13.8 & & \\
$\quad$ Hispanic & 14.2 & 28.7 & 42.5 \\
African American & 9.0 & 20.1 & 34.3 \\
Asian & 11.3 & 12.8 & 21.8 \\
Grade/age & 9.8 & 25.7 & 37.0 \\
2 (7-8 years) & 14.7 & 24.5 & 34.3 \\
3 (8-9 years) & 17.7 & 21.1 & 35.8 \\
4 (9-10 years) & & 24.9 & 42.6 \\
5 (10-11 years) & & & \\
\hline
\end{tabular}

between genders, with $32.7 \%$ of male compared with $27.8 \%$ of female 6-11-year-old children being overweight or at risk ${ }^{5}$. This difference between sexes was even more pronounced among Mexican American children, with 43\% of male versus $35.1 \%$ of female 6-11-year-old children being overweight or at risk ${ }^{5}$.

The present study also reports that the overweight children had a wide range of degrees of overweight. NHANES III also found a population of children who were extremely overweight compared with the earlier studies, NHANES I and $\mathrm{II}^{1,5,17,18}$. In other words, the heaviest children are getting markedly heavier. This trend towards a heavier population of children is disturbing since the more overweight an individual is as a child, the more likely $\mathrm{s} /$ he is to become overweight as an adult ${ }^{10,11}$

Certain racial and economic groups in the USA are at higher risk for morbidities associated with obesity. In our study sample, the prevalence of overweight children is the highest among the African American and Hispanic children; Hispanics had the highest prevalence of being overweight $(28.7 \%)$, followed by African Americans (20.1\%). These overweight rates are higher than the rates from a national US sample in 1999-2000 (NHANES III): $19 \%$ of non-Hispanic black children and $23.7 \%$ of Mexican American children aged 6-11 years 5 .

African American and Hispanic populations are at higher risk for developing the associated morbidities of obesity that include type II diabetes, hypertension and cardiovascular disease 9 . Type II diabetes is already being found in children below 10 years of age; the American Dietetic Association recommends screening for type II diabetes starting at the age of 10 years among high-risk children $^{22,23}$. In addition, the children we studied were from the lower socio-economic groups who represent a particularly vulnerable population for becoming overweight $^{24}$. In turn, being overweight could potentially perpetuate or be a cause of continuing poverty 9 . Overweight is, for example, associated with interfering with employment opportunities and limiting social opportunities $^{25,26}$.

The finding that there were relatively low levels of underweight in this study is consistent with other US reports. However, the Community Childhood Hunger Identification Project and other surveys reported that widespread hunger exists in the USA ${ }^{27-29}$. The presence of both reports of hunger and high rates of overweight in the same population appears paradoxical; however, these may actually be highly correlated, especially in lowincome families who experience food insecurity ${ }^{24}$.

The high rate of overweight among US children is due to an energy imbalance between consumed and expended energy $^{30}$. An interconnected series of environmental, biological and behavioural factors leads to the overweight condition, such as a high-fat and high-calorie diet combined with an increased sedentary lifestyle associated with viewing television and playing video games ${ }^{31}$. Moreover, declining opportunities for outdoor active play in unsafe neighbourhoods and drastic reductions in physical education programmes in inner-city schools, particularly in Los Angeles, contribute to the problem. The California state-mandated time for physical education is 100 min per week, often administered by the classroom teacher. Teachers usually have little training and no physical education equipment to perform simple physical activity programmes. In addition, most elementary schools located in poverty areas are without physical education teachers or coaches.

Designing a primary obesity prevention school-based programme plus parent education is a practical solution to the complex problem of obesity. Children of elementary school age in the lower socio-economic groups eat the majority of their meals at school and they have the most opportunity for organised physical activity during school and in after-school programmes ${ }^{31}$. Our findings and a review of the literature suggest that intervention programmes to prevent and reduce obesity in high-risk 
populations such as those found in LAUSD need urgently to be introduced well before and during elementary school $^{31-35}$.

\section{Study constraints}

A sampling bias may have occurred because this study was strictly voluntary and so children or families who were more or less interested or concerned about nutritional issue may have volunteered more or less often to participate in the study. We did not gather information from those who did not participate in the study; however, the racial and ethnic mix in our sample reflects the general population of the children in the 14 schools studied.

\section{Problems with BMI and TSF measurements}

It is a step forward not to have to rely only on adult cut-offs for BMI to define at risk for overweight and overweight among children because not all overweight children were being identified using adult cut-offs; however, using BMI to identify overweight children is still somewhat problematic. It necessitates an accurate height measurement. Moreover, Troiano and Flegal $^{3}$ caution about using BMI as a measure of body composition in children and adolescents, because the components that contribute to the total measure of BMI change during growth and maturation. These include body proportions, bone mass, the ratio of lean to fat tissue and stage of puberty. Also of note is that BMI is not independent of height in children and adolescents since BMI changes with age. Children with long-standing overweight tend to be taller than their non-overweight counterparts. Thus BMI could be lower because height is in the denominator. Conversely, short children of normal weight or only slight overweight, who are even slightly stunted, could have an elevated BMI owing to the lower height in the denominator. However, despite the above problems raised with BMI, it is considered a practical screening method by the American Academy of Pediatrics to identify children who are overweight because of the routine measurement of height and weight in health-care settings, it correlates well with more accurate measure of fatness and co-morbid conditions in adults and children, and the new BMI norms for children according to age and sex help provide a guide for early detection of at risk for overweight among children ${ }^{36}$.

Obtaining accurate TSF in overweight children is also problematic. There are racial differences in fat distribution. For instance, African Americans have a relatively smaller amount of fat deposition in the TSF compared with other sites in the body. Although TSF is a direct measure of body fat, its measurement in an overweight individual may be extremely difficult and the calliper jaws may not be able to compress the tissue to obtain an accurate measurement. However, the study fieldworkers had a high percentage of agreement with repeat measurements by an expert: $86 \%$ of TSF measurements were within $3 \mathrm{~mm}$. In addition, the
Pediatric Obesity Evaluation and Treatment Expert Work Committee point out that TSF higher than the 95th percentile, measured by an experienced person, can help distinguish between a child with excess fat rather than increased lean body mass or large frame size ${ }^{37}$.

\section{Action stimulated by the study findings}

The findings of high prevalence of at risk for overweight and overweight among children in LAUSD have triggered LAUSD policy-makers to develop pilot projects to help address this nutritional problem. The projects developed in LAUSD following this research include a salad bar lunch menu option, programmes focused on nutrition education, school-based garden projects and enhancement of physical activity programmes through the in-service training of classroom teachers. In response to the preliminary findings of our survey, a salad bar programme was launched in 1999 by LAUSD Food Services as a pilot project in three schools, just a year after our study took place. The salad bar lunch menu option is an alternative to the hot lunch menu option and is now operational in over 30 LAUSD elementary schools. It offers a choice of fruits and vegetables along with representative foods from the other food groups. The salad bar programme is now expanding to yet more schools as a fruit and vegetable bar to augment the hot lunch food offerings within LAUSD. This expansion being assisted by a partnership with a nutrition education programme entitled LAUSD Nutrition Network. This programme began in the year 2000 and focuses on integration of nutrition education in the curriculum of elementary, middle and high schools in LAUSD. It is available for all Title 1 (schools eligible for the federal government subsidised free or reduced price lunch and breakfast programme) schools to participate. The programme director utilised the findings of our study to support her application to get funding. The LAUSD Nutrition Network supports activities that include, in addition to the salad bar, the development of school gardens and physical activity programmes. Finally, the enhancement of physical activity through the in-service education (the SPARK programme) of teachers took place in three schools that were part of the original 14 in our study. The principals and teachers agreed to participate in this in-service educational programme because, on the basis of our study results, they recognised the need to promote healthy lifestyles among the children in their schools. One way to promote healthy lifestyles is to enhance physical activity programmes during school hours. Each of these intervention programmes is currently being formally evaluated.

The policy-makers who are the leaders in the above intervention programmes were kept informed and involved in our study throughout its planning, implementation and data analysis phases. We held periodic meetings, asked for their suggestions and input in the research design and fed back the results during the data 
analysis. We feel that their early and on-going participation with our research facilitated the process of action through research. This academic and policy-maker collaboration is a strategy that can facilitate programme implementation that responds to the health needs within individual school districts. We feel we took a first step in translational research by developing baseline local data that provided the stimulus for innovative interventions within LAUSD.

\section{Conclusions and comments}

There are high prevalence rates of at risk for overweight and overweight children among the low-income, Hispanic and African American schoolchildren. Obesity has serious consequences for their future health. Primary obesity prevention and treatment programmes targeting these high-risk groups are urgently needed in elementary schools to help reduce this escalating public health disaster. Former Surgeon General Satcher identified the school environment as one of the essential areas to be modified to promote optimal nutrition in The Surgeon General's Call to Action to Prevent and Decrease Overweight and Obesity ${ }^{35}$. The value of generating local data to define health problems within a specific community is demonstrated by the proliferation of programmatic and policy changes that is taking place in LAUSD as a result of the preliminary results of this study. In addition, 'translational research' was better accomplished through the involvement of the decision-makers from the start of the survey design.

\section{Acknowledgements}

This work was funded by The Joseph D Drown Foundation. The authors wish to thank Dan Neumann and Susi Cohen and Leda Nemer, MPH for their assistance.

\section{References}

1 Troiano RP, Flegal KM, Kuczmarski RJ, Campbell SM, Johnson CL. Overweight prevalence and trends for children and adolescents: the National Health and Nutrition Examination Surveys, 1963 to 1991. Archives of Pediatric $\&$ Adolescent Medicine 1995; 149: 1085-91.

2 Wolfe WS, Campbell CC, Frongillo EA, Haas JD, Melnick TA. Overweight schoolchildren in New York State: prevalence and characteristics. American Journal of Public Health 1994; 84: $807-13$.

3 Troiano RP, Flegal KM. Overweight children and adolescents: description, epidemiology, and demographics. Pediatrics 1998; 101(Suppl.): 497-504.

4 Gortmaker SL, Dietz WH Jr, Sobol AM, Wehler CA. Increasing pediatric obesity in the United States. American Journal of Diseases of Children 1987; 141: 535-40.

5 Ogden CL, Flegal KM, Carroll MD, Johnson CL. Prevalence and trends in overweight among US children and adolescents, 1999-2000. Journal of the American Medical Association 2002; 288: 1728-32.

6 Ogden CL, Troiano RP, Briefel RR, Kuczmarski RJ, Flegal KM, Johnson CL. Prevalence of overweight among preschool children in the United States, 1971 through 1994. Pediatrics 1997; 99: E1.
7 Mei Z, Scanlon KS, Grummer-Strawn LM, Freedman DS, Yip R, Trowbridge FL. Increasing prevalence of overweight among US low income preschool children: The Centers for Disease Control and Prevention, Pediatric Nutrition Surveillance, 1983 to 1995. Pediatrics 1998; 101(1): E12.

8 Neufeld WD, Raffel LJ, Landon C, Chen YDI, Vadheim CM. Early presentation of type 2 diabetes in Mexican-American youth. Diabetes Care 1998; 21: 80-6.

9 Dietz WH. Health consequences of obesity in youth: childhood predictors of adult disease. Pediatrics 1998; 101(Suppl.): 518-25.

10 Gill TP. Key issues in the prevention of obesity. British Medical Bulletin 1997; 53: 359-88.

11 Guo SS, Qu W, Chumlea WC, Roche AF. Predicting overweight and obesity in adulthood from body mass index values in childhood and adolescence. American Journal of Clinical Nutrition 2002; 76: 653-8.

12 http://grants.nih.gov/grants/guide/pa-files/PA-02-061.html

13 Jelliffe DB, Jelliffe EFP. Community Nutritional Assessment. Oxford: Oxford University Press, 1989.

14 Lohman TG, Roche AF, Martorell R, eds. Anthropometric Standardization Reference Manual. Champaign, IL: Human Kinetics Books, 1988.

15 Centers for Disease Control and Prevention (CDC)/World Health Organization (WHO). EPI INFO 6, Version 6.02. Atlanta, GA/Geneva: CDC/WHO, 1994.

16 National Center for Health Statistics (NCHS). NCHS Growth Curves for Children, Birth-18 years. Vital and Health Statistics \#65. Hyattsville, MD: Public Health Service, 1977, $78-165$.

17 National Center for Health Statistics (NCHS). The First National Health and Nutrition Examination Survey, 197174 (NHANES I). Hyattsville, MD: NCHS, 1974.

18 National Center for Health Statistics (NCHS). The Second National Health and Nutrition Examination Survey, 197680 (NHANES II). Hyattsville, MD: NCHS, 1980.

19 Centers for Disease Control and Prevention (CDC)/National Center for Health Statistics (NCHS). BMI Index for Age Percentiles for Boys and Girls 2 to 20 years. Atlanta, GA/Hyattsville, MD: CDC/NCHS, 2000.

20 Dietz WH, Belizzi MC. Introduction: the use of BMI to assess obesity in children. American Journal of Clinical Nutrition 1999; 70(Suppl.): $123 \mathrm{~s}-5 \mathrm{~s}$.

21 Frisancho AR. New norms of upper limb fat and muscle areas for assessment of nutritional status. American Journal of Clinical Nutrition 1981; 34: 2540-5.

22 American Diabetes Association. Type 2 diabetes in children and adolescents. Diabetes Care 2001; 22: 381-96.

23 Hale D. Treating youths with type 2 diabetes. Clinical update. Pediatric Endocrinology 2001; 4(1): 1.

24 Dietz WH. Does hunger cause obesity? Pediatrics 1995; 95 : $767-76$.

25 Khaodhiar L, McCowen KC, Blackburn GL. Obesity and its comorbid conditions. Clinical Cornerstone 1999; 2: 17-21.

26 Siedell JC. Societal and personal costs of obesity. Experimental and Clinical Endocrinology \& Diabetes 1998; 106(Suppl. 2): 7-9.

27 Food Research and Action Center. Update to the nutrition provisions of the new GOP welfare reform bills (HR 3732 and S 1795). Email received 16 July 1996.

28 Kleinman RE, Murphy JM, Little M, Pagano M, Wehler CA, Regal $\mathrm{K}$, et al. Hunger in children in the United States: potential behavioral and emotional correlates. Pediatrics 1998; 101(1): E3.

29 Physician Task Force on Hunger in America. Hunger in America: The Growing Epidemic. Boston, MA: Harvard University School of Public Health, 1985.

30 Dietz W, Gortmaker S. Preventing obesity in children and adolescents. Annual Review of Public Health 2001; 22: $337-53$. 
31 Luepker R, Perry C, McKinlay S, Nadar P, Parcel G, Stone E, et al. Outcomes of a field trial to improve children's dietary patterns and physical activity: the Child and Adolescent Trial for Cardiovascular Health (CATCH). Journal of the American Medical Association 1996; 275: 768-76.

32 Sallis J, McKenzie T, Alcarez J, Kolody B, Faucette N, Hovell M. The effects of a 2-year physical education program (SPARK) on physical activity and fitness in elementary school students. American Journal of Public Health 1997; 87: 1328-34.

33 Snyder P, Anliker J, Cunningham-Sabo L, Dizon L, Altaha J, Chamberlain A, et al. The Pathways Study: a model for lowering the fat in school meals. American Journal of Clinical Nutrition 1999; 69(Suppl.): 810S-5S.
34 Teufel N, Perry C, Story M, Flint-Wagner H, Levin S, Clay T, et al. Pathways family intervention for third-grade American Indian children. American Journal of Clinical Nutrition 1999; 69(Suppl.): 803S-9S.

35 US Department of Health and Human Services. The Surgeon General's Call to Action to Prevent and Decrease Overweight and Obesity. Washington, DC: Government Printing Office, 2001.

36 Kreb NF, Jacobson MS. American Academy of Pediatrics Committee on Nutrition. Prevention of pediatric overweight and obesity. Pediatrics 2003; 112(2): 424-30.

37 Barlow SE, Dietz WH. Obesity Evaluation and Treatment Expert Committee Recommendations [onlinel, 1998. Available at http://www.pediatrics.org/cgi/content.full.102/3/e29 